\title{
Identifying the Factor of Employee Wellbeing towards the Engagement of Employee in Gojek Bandung Company
}

\author{
Vega Allya Hedina ${ }^{1}$, Nur Arief Rahmatsyah Putranto ${ }^{2}$ \\ \{vega_allya@sbm-itb.ac.id ${ }^{1}$ \} \\ Institut Teknologi Bandung, Indonesia ${ }^{1,2}$
}

\begin{abstract}
Employee wellbeing is becoming a critical concept to boost employee engagement in a company. Employee wellbeing and engagement run hand-in-hand as it has a positive relationship and builds off of one another. When the employee is happy and feels content with their job, it does affect their wellbeing. As well as when the employee is physically and mentally healthy, they will also feel happier in the workplace thus contributing to better performance. However, employees that are highly engaged demonstrate a much workload in which the condition might cause stress for employees consequently affect their wellbeing. This condition occurred in one of the leading startup companies named Gojek, specifically for the employees in Bandung Region. A survey indicates a low number of employees agreed that their amount of stress is manageable. Meanwhile, manageable stress has a strong correlation with employee engagement. This study has aimed to identify the factor of employee wellbeing that could engage the employees. The data were processed using Multiple Linear Regression to identify which independent variable significantly affected the dependent variable. The research found that from the five factors, only Financial Wellbeing has a significant correlation with the employee engagement in Gojek Company in Bandung Region. Therefore, it is important for the company to develop employee wellbeing initiatives programs that focus on the employees' financial wellbeing in order to improve employee wellbeing and maintain employee engagement in a good state.
\end{abstract}

Keywords: Employee Wellbeing, Employee Engagement, Employee Wellbeing Initiatives, Startup Company, Multiple Linear Regression

\section{Introduction}

The public-list companies of the agriculture sector in Indonesia seems not attractive enough for investors. The Investment Coordinating Board (BKPM in Indonesia-red) in January 2018 has released domestic investment data (PMDN in Indonesia-red) and foreign investment data (PMA in Indonesia-red) for the 4th Quarter 2017 whose figured out around IDR692,8 trillion. That figure has risen to $13,05 \%$ from the investment of PMDN and PMA in 2016 for the same period. However, the agricultural sector only reached $8,1 \%$ out of the total investment or around IDR14,6 trillion.

Human resources are the most significant assets of a company to support company's activities by utilizing their potential and ability. The effectively and efficiently used of human talent as the development human resources in formal organization system has a significant contribution to achieve organizational objectives [1]. A company can achieve competitive 
advantages by putting concern to this human factor since business organizations is a group of people who interact with each other to perform and function to achieve the goals of organization [2]. The strategic importance of human resources lies in the fact that a company's long-term success and failure relies upon the existence of the right people at the right place at the right time [3]. Not only for large companies, startup companies also need the role of HR to support the development of the company. According to Workable.com (2019), a strong HR practices in startup company showed better position to develop and retain their employees. No exception for Gojek Company, where the HR generally functions to review and evaluate employees and firm performances, motivate the human power to generate a favorable output, and is responsible for giving rewards to the outstanding employees as to maintain their performance.

Ries [4] on his book, defines startup as an "organization dedicated to creating something new under conditions of extreme uncertainty". PT Aplikasi Karya Anak Bangsa or well-known as Gojek, currently become Indonesia's first decacorn startup as of the first quarter of 2019, its valuation hit US\$ 10 billion according to CB Insights [5]. The company initial focus is to gather ojek drivers to be operate effectively and organized through one integrated application. The company then continues to grow and create innovations that become a solution to solve societies' daily needs. Currently expand its services in various lifestyle specialties in the form of GoRide, GoCar, GoMed, GoMart, GoShop, GoSend, GoMassage, GoClean, GoFitness, GoFood, GoTix, GoPlay, GoNews, GoPulsa, GoNearby, GoBills, GoPoints, GoSure, GoBluebird, and GoBox under its mobile apps named Gojek. With the range of programs that are run, Gojek has a large number of employees to support the running of the program. According to Gojek [6], the average age of its employees is 29 years old, which is included as millennial employee or from Generation Y. According to Kasasa [7], Generation Y is people who are born between 1980 and 1994 (current minimum age is 26).

Along with a study conducted by Dale Carnegie Indonesia in 2016, titled "Employee Engagement Among Millennials" with objectives is to determine to what extent is Indonesian employees are engaged to their organization. The survey shows that $9 \%$ of millennial employees refused to engage or disengaged to the company, following to $66 \%$ of millennial employees that are partially engaged, and only $25 \%$ of millennial workforce are fully engaged with the organization or company they are work for. Moreover, can be seen from the survey that from millennial workforces who are fully engaged, $60 \%$ of millennial employees plan to resign if they feel disengaged with the company or organization.

Employees that are engaged tend to perform better, enhance productivity and lessen employee turnover. For that reason, employee engagement has become a subject matter in organizations as it directly impacts to the growth and development of the company. The extent of employee engagement is to which the workforce is committed to the mission, vision, and goal of the organization [8]. According to Gorgievski et al. [9], research shows positive results between individuals and organizations when employees are engaged.

Kohll [10] argued that employee engagement and wellbeing run hand-in-hand as it has positive relationship and builds off of one another. When the employee happy and feel content of their job, it does affect their wellbeing. As well as when the employee is physically and mentally healthy, they will also feel happier in the workplace thus contribute to a better performance. Based on Employee Engagement Index survey by Gallup [11], asking how work lives benefit employees' psychological health, a 78\% majority of engaged employees feel their work lives have benefit them psychologically, following to $48 \%$ of not-engaged employees and $15 \%$ actively disengaged employees saying the same benefit. Based on data mentioned, it shows that the condition of work life has an impact towards employees' wellbeing. According to Islam 
[12], one of six factors that have a significant influence on the quality of work life is working environment and condition.

Working environment is formed by company culture, it is a shared value, belief system, and attitudes that shared by all of the stakeholders in a workplace. Many companies have its own strategic organizational management that influence company culture to a certain extent, especially in Gojek Indonesia. Identifying employee reviews from Gojek [6], the organization has an innovative and inclusive culture that allows the employee to move fast and think different to solve difficult problems. Gojek gives a freedom to its employees to have a high initiative and experimenting raw ideas into shaping the end product. Moreover, as mentioned by Gojek Tech, the company does not have "office timings", usually called "9 to 5 job". Hence, they have a flexible working hours and flexible working place for the employee to complete their works. However, identifying from the working culture it has, usually it is resulting in more working hours than the regular working hours for the Gojek employees to work or perform. Highly working hours demonstrate a (too) highly engaged employee. Hancock and Cooper [13] argued that employees that are highly engaged does not always mean to have high wellbeing. This does even mean that when the employees are highly engaged, they probably have too much workload and have working for too many hours. Not infrequently they fail to take breaks or time off consequently impact their wellbeing and productivity if they reach burnout at the end. This condition also impacting firms' performance and productivity.

On the other hand, Gojek as a startup company has to move fast in order to catch up to market demand and also to face fierce competition among the competitors. Based on this condition, it is important for Gojek to maintain employee performance as it is become the core resources. One key thing that Gojek can do to maintain the performance of the employee is to keep employee wellness.

\section{Research Methods}

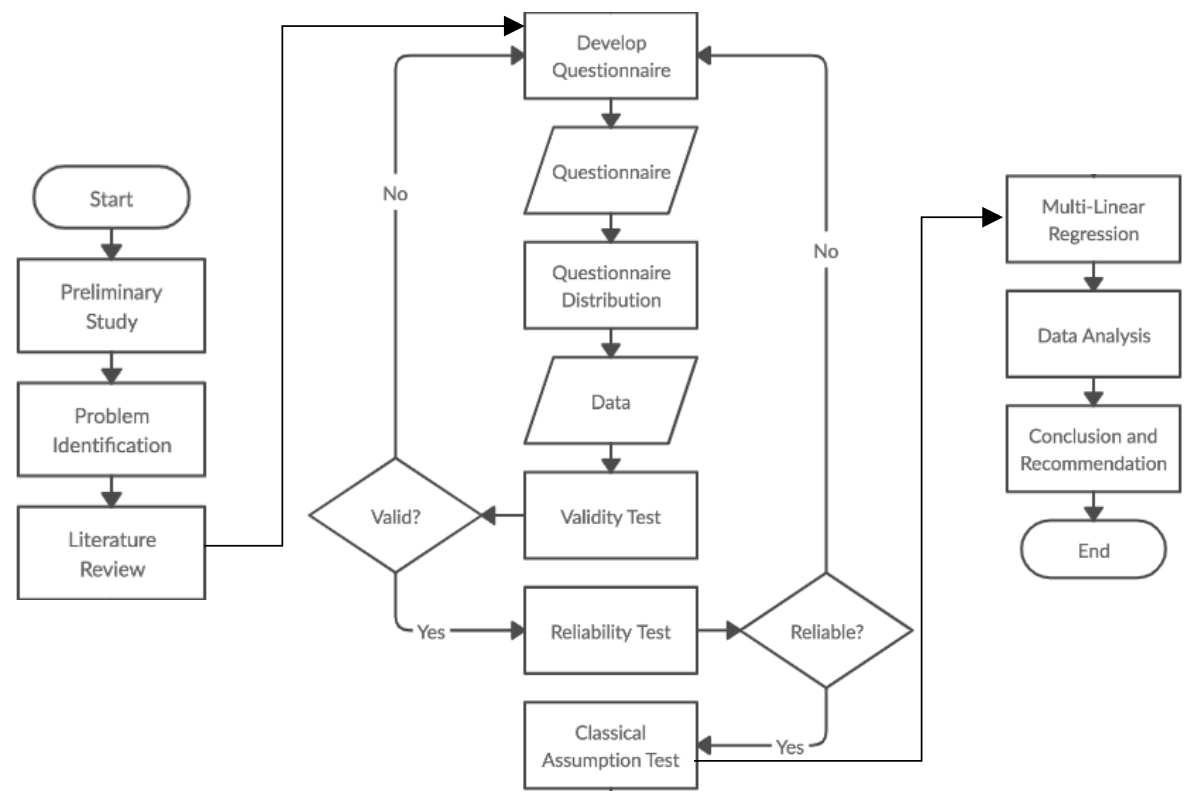




\section{Result and Discussion}

\subsection{Validity and Reliability}

In order to test the accuracy of a concept used to measures the variable that intended to be measured, validity test needs to be implemented in a quantitative study. Validity test conducted using Pearson Correlation Coefficient by correlating the value of $\mathrm{R}$ count with the $\mathrm{R}$ table value. The question will be considered as valid if the value of $\mathrm{R}$ arithmetic $>\mathrm{R}$ table and shows positive value. As the second measure in quantitative study is reliability. Reliability relates to the consistency of a measure which testing the extent to which a research instrument shows a consistent result. In order to test the reliability of the data, the researcher used the Cronbach's alpha. Therefore, the result of validity and reliability test can be seen in the table 1 and table 2 .

Table 1. Validity Test

\begin{tabular}{|c|c|c|c|}
\hline Group Item & Item & Pearson's R & Validity \\
\hline \multirow{3}{*}{ CR_WB } & Q1 & 0.859 & Valid \\
\cline { 2 - 4 } & Q2 & 0.815 & Valid \\
\cline { 2 - 4 } & Q3 & 0.867 & Valid \\
\hline \multirow{3}{*}{ SOC_WB } & Q1 & 0.760 & Valid \\
\cline { 2 - 4 } & Q2 & 0.867 & Valid \\
\cline { 2 - 4 } & Q3 & 0.824 & Valid \\
\hline \multirow{4}{*}{ FIN_WB } & Q1 & 0.795 & Valid \\
\cline { 2 - 4 } & Q2 & 0.806 & Valid \\
\cline { 2 - 4 } & Q3 & 0.779 & Valid \\
\hline \multirow{4}{*}{ PY_WB } & Q1 & 0.856 & Valid \\
\cline { 2 - 4 } & Q2 & 0.838 & Valid \\
\cline { 2 - 4 } & Q3 & 0.795 & Valid \\
\hline \multirow{3}{*}{ CM_WB } & Q1 & 0.893 & Valid \\
\cline { 2 - 4 } & Q2 & 0.733 & Valid \\
\cline { 2 - 4 } & Q3 & 0.883 & Valid \\
\hline \multirow{5}{*}{ EMP_EG } & Q1 & 0.792 & Valid \\
\cline { 2 - 4 } & Q2 & 0.849 & Valid \\
\cline { 2 - 4 } & Q3 & 0.873 & Valid \\
\cline { 2 - 4 } & Q4 & 0.782 & Valid \\
\cline { 2 - 4 } & Q5 & 0.798 & Valid \\
\cline { 2 - 4 } & Q6 & 0.868 & Valid \\
\hline
\end{tabular}

$* \mathrm{df}=31, \mathrm{R}$ Table $=0.344$

The outcome of $\mathrm{R}$ table is 0.344 ( $\mathrm{df}=31$ and confidence level $=95 \%)$. From the table above it can be interpreted that the correlation coefficient of all variable is higher than the $\mathrm{R}$ table. Therefore, the data is known as a valid data.

Table 2. Reliability Test

\begin{tabular}{|c|c|c|}
\hline Group Item & Cronbach's Alpha & Reliability \\
\hline CR_WB & 0.802 & Reliable \\
\hline SOC_WB & 0.750 & Reliable \\
\hline FIN_WB & 0.691 & Reliable \\
\hline
\end{tabular}




\begin{tabular}{|c|c|c|}
\hline PY_WB & 0.765 & Reliable \\
\hline CM_WB & 0.784 & Reliable \\
\hline EMP_EG & 0.899 & Reliable \\
\hline
\end{tabular}

$* \mathrm{~N}=33$, Reliability at 0.6

Moreover, as for the reliability test, the overall Cronbach's alpha value is more than 0.6 which indicate the data is reliable.

\subsection{Validity and Reliability}

\subsubsection{Normality Test}

Normality test is used to determine whether the data is normally distributed or not. The data that has normal distribution is determined as a good data and can be distinguished from the level of skewness. Standardized residual data that tend to be skewed to the right is called negative skewness, if the residual data tend to be skewed to the left is called positive skewness. Therefore, the data is said to be normal if the skewness is symmetrical. The result of the normality test can be seen in the figure 1 .

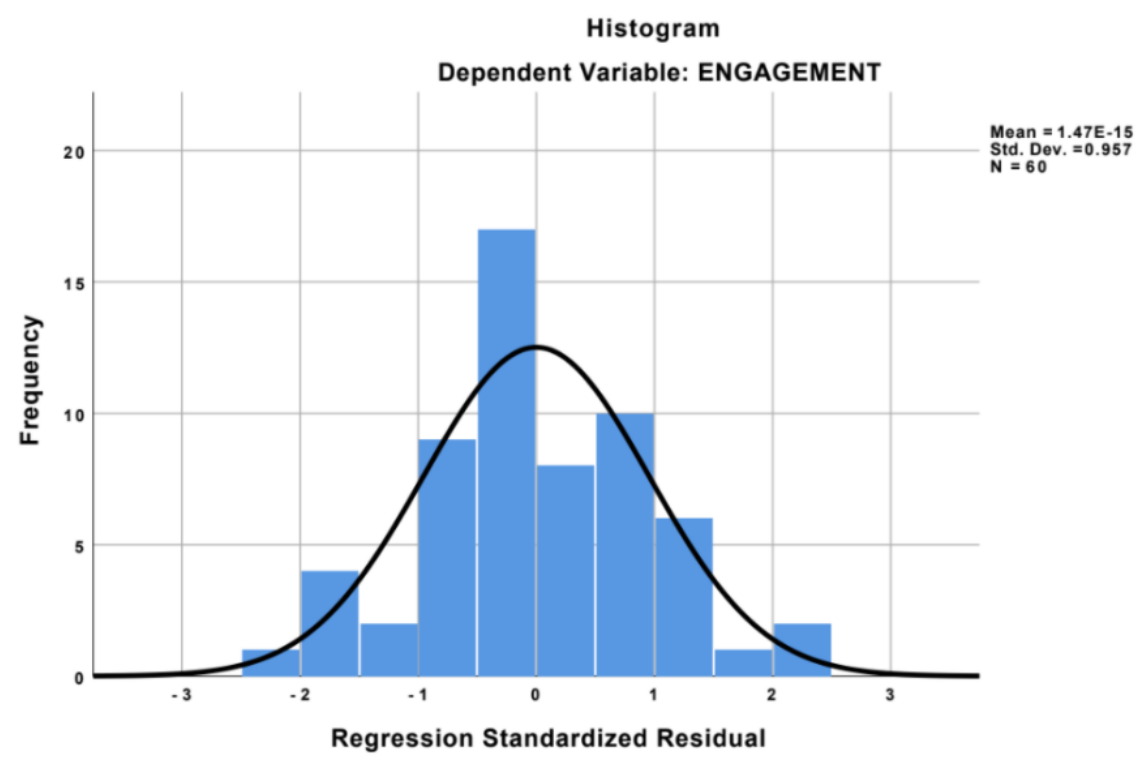

Fig. 1. Normality Test

Based on the figure 1, the standardized residual data has formed zero or symmetrical skewness $($ Median $=$ Mean $=$ Mode $)$, which implies the data has spread evenly or normally distributed.

\subsubsection{Multicollinearity Test}

Multicollinearity test is used to find out the high correlation existed between independent and dependent variables in a multiple regression model. The data can be said no multicollinearity by looking at the Value Inflation Factors (VIF) and Tolerance. As the basic of 
decision, there is no multicollinearity if VIF $<10$ and the value of Tolerance $>0.10$. The result of multicollinearity test in this research is shown on the table 3.

Table 3. Multicollinearity Test

\begin{tabular}{|l|c|c|c|c|c|}
\hline \multicolumn{2}{|c|}{ Table 3. Multicollinearity Test } \\
\hline \multirow{2}{*}{1} & Model & $\begin{array}{c}\text { 95.0\% Confidence } \\
\text { Lower Bound }\end{array}$ & $\begin{array}{c}\text { Interval for B } \\
\text { Upper Bound }\end{array}$ & $\begin{array}{c}\text { Collinearity } \\
\text { Tolerance }\end{array}$ & $\begin{array}{c}\text { Statistics } \\
\text { VIF }\end{array}$ \\
\cline { 2 - 6 } & $($ Constant) & -2.373 & 1.218 & & \\
\cline { 2 - 6 } & Career & -.036 & .633 & .640 & 1.562 \\
\cline { 2 - 6 } & Social & -.187 & .564 & .303 & 3.295 \\
\cline { 2 - 6 } & Financial & .036 & .718 & .371 & 2.697 \\
\cline { 2 - 6 } & Physical & -.485 & .263 & .238 & 4.200 \\
\cline { 2 - 6 } & Community & -.065 & .783 & .253 & 3.952 \\
\hline
\end{tabular}

According to the table 3, the Tolerance value of each variables are greater than 0.10 with details: Career (0.640), Social (0.303), Financial (0.371), Physical (0.238), and Community (0.253). Moreover, the VIF had values less than 10 with details: Career (1.562), Social (3.295), Financial (2.697), Physical (4.200), and Community (3.952). Based on the test, there is no high correlation between the dependent variables or indicates as no multicollinearity.

\subsubsection{Heteroscedasticity Test}

Heteroscedasticity test is conducted to see if there was a regression model residual variance inequality from one observation to another. According to Ghozali (2007), a data was indicated heteroscedasticity if the residual variance is not constant. Heteroscedasticity can be seen from the value of significant by using Glejser Test method. The data has no heteroscedasticity if the significance value $>0.05$. The result can be seen in the table 4 .

Table 4. Heteroscedasticity Test

\begin{tabular}{|c|l|c|c|c|c|c|}
\hline \multirow{2}{*}{ Model } & \multicolumn{2}{|c|}{$\begin{array}{c}\text { Unstandardized } \\
\text { Coefficients }\end{array}$} & $\begin{array}{c}\text { Standardized } \\
\text { Coefficients }\end{array}$ & \multirow{2}{*}{ t } & \multirow{2}{*}{ Sig. } \\
\cline { 3 - 7 } \multicolumn{2}{|c|}{} & B & Std. Error & Beta & & \\
\hline \multirow{3}{*}{1} & (Constant) & 1.714 & .476 & & 3.602 & .001 \\
\cline { 2 - 7 } & Career & .116 & .089 & .190 & 1.306 & .197 \\
\cline { 2 - 7 } & Social & -.150 & .099 & -.319 & -1.507 & .138 \\
\cline { 2 - 7 } & Financial & -.171 & .090 & -.363 & -1.897 & .063 \\
\cline { 2 - 7 } & Physical & .131 & .099 & .315 & 1.321 & .192 \\
\cline { 2 - 7 } & Community & -.133 & .112 & -.274 & -1.184 & .241 \\
\hline
\end{tabular}

Based on the Table 4.4, the significant value of all variables has value higher than 0.05 which indicates there is no heteroscedasticity in this data.

\subsubsection{Linearity Test}

Linearity test is used to find out whether or not the variables have a significant linear relationship. The linearity of data can be seen from the P-P Plot when the distribution of standardized residual data is following the normality line such as the result of linearity test in the figure 2 . 
Normal P-P Plot of Regression Standardized Residual

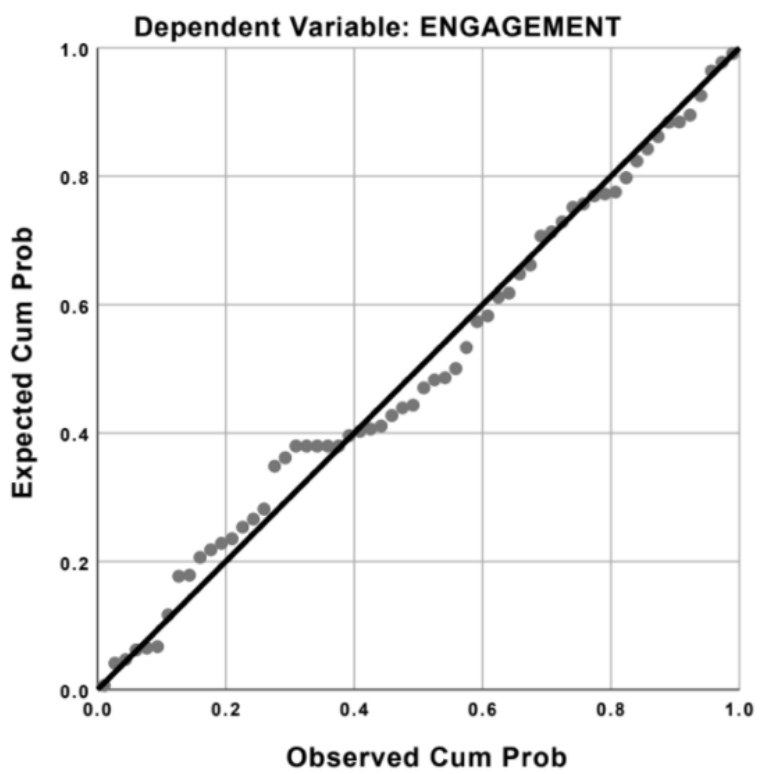

Fig. 2. Linearity Test

Based on the P-P Plot in the Figure 4.2, the point of distributions is following the diagonal lines, hence the result of linearity test in this study indicates there is a linear relationship between variables.

\subsection{Multiple Linear Regression}

Multiple regression analysis is a multivariate technique which used when the research has more than one independent variable and one dependent variable. The regression coefficient will indicate the relative importance of each independent variables in the prediction of the dependent variable. Prior to conducting Multiple Linear Regression, the data must past the Classic Assumption Test first. The analysis of multiple regression can be shown in the table 5, table 6 , and table 7 .

Table 5. ANOVA

\begin{tabular}{|c|l|c|c|c|c|c|}
\hline \multicolumn{2}{|c|}{ Model } & Sum of Squares & Df & Mean Square & F & Sig. \\
\hline \multirow{3}{*}{1} & \begin{tabular}{l} 
Regression \\
Residual \\
\cline { 2 - 7 }
\end{tabular} & 31.929 & 5 & 6.386 & 13.546 & $.000^{\mathrm{b}}$ \\
\cline { 2 - 7 } & Total & 25.456 & 54 & .471 & & \\
\cline { 2 - 7 } & 57.386 & 59 & & & \\
\hline
\end{tabular}

a. Dependent Variable: Engagement

b. Predictors: (Constant), Community, Career, Financial, Social, Physical

Based on the analysis using ANOVA, the regression model is a fit used in this study and shows the $\mathrm{F}(5,54)=13.546$, and p-value (Sig.) is 0.000 , which less than 0.05. Consequently, all the independent variables (Career, Social, Financial, Physical, Community) has significantly predict the dependent variable (Employee Engagement) simultaneously. 
Table 6. Model Summary Table

\begin{tabular}{|c|c|c|c|c|c|}
\hline Model & $\mathbf{R}$ & R Square & $\begin{array}{c}\text { Adjusted R } \\
\text { Square }\end{array}$ & $\begin{array}{c}\text { Std. Error of } \\
\text { the Estimate }\end{array}$ & $\begin{array}{c}\text { Durbin- } \\
\text { Watson }\end{array}$ \\
\hline 1 & $.746^{\mathrm{a}}$ & .556 & .515 & .68660 & 2.563 \\
\hline
\end{tabular}

a. Predictors: (Constant), Community, Career, Financial, Social, Physical

b. Dependent Variable: Engagement

In the Model Summary table, the R, R2, adjusted R2, and the Std. Error of estimate is used to determine how fits the regression model to the data. Based on the Table $\mathrm{x}$, the independent variables explain $51.5 \%$ of the variability of the dependent variable.

Table 7. Multiple Linear Regression Test

\begin{tabular}{|c|l|c|c|c|c|c|}
\hline \multicolumn{2}{|c}{ Model } & \multicolumn{2}{|c|}{$\begin{array}{c}\text { Unstandardized } \\
\text { Coefficient }\end{array}$} & $\begin{array}{c}\text { Standardized } \\
\text { Coefficients }\end{array}$ & \multirow{2}{*}{ t } & \multirow{2}{*}{ Sig. } \\
\cline { 3 - 7 } \multicolumn{2}{|c|}{} & B & Std. Error & Beta & & \\
\hline \multirow{3}{*}{1} & (Constant) & -.577 & .896 & & -.645 & .522 \\
\cline { 2 - 7 } & Career & .298 & .167 & .203 & 1.791 & .079 \\
\cline { 2 - 7 } & Social & .189 & .187 & .166 & 1.008 & .318 \\
\cline { 2 - 7 } & Financial & .377 & .170 & .330 & 2.219 & .031 \\
\cline { 2 - 7 } & Physical & -.111 & .187 & .110 & -.595 & .555 \\
\cline { 2 - 7 } & Community & .359 & .211 & .306 & 1.699 & .095 \\
\hline
\end{tabular}

In order to determine whether the hypothesis is accepted or rejected, each variable must have level of significance below 0.05. Based on the Multiple Linear Regression test, Financial is the only accepted hypothesis with significance level 0.031, whereas Career, Social, Physical, and Community are rejected hypothesis because the value of significance level is $>0.05$.

\subsection{Discussion}

Financial Wellbeing is one out of the five factor of employee wellbeing that have significant correlation with Employee Engagement. The result of the Multiple Linear Regression shows that the engagement of employees in Gojek Bandung company could raise if they have a good state of financial wellbeing. This condition occurs because when people have good wellbeing of financial, it does imply that someone will not feel forced or stressed about making choices by considering their baseline expenses or necessities [14]. The absence of feeling stress about finances both in the short-term and long-term events can help the employee to focus on their performances thus improve their engagement. Additionally, fostering financial wellbeing for employees at an organizational level is a part of Corporate Social Responsibility goals and has been proven by Arendt and Brettel [15] to have a contribution to improving the company's image. A positive image of a company is an important aspect to increase employee engagement which by Aon Hewitt is one of the three observable factors of employee engagement, specifically for the "Say" factor [16]. The positive image that the company has can make the employees utter good things about the company to coworkers, potential employees, and customers.

Career Wellbeing in the result of the Multiple Linear Regression test has a barely detectable statistically significant difference with significance value of 0.079 . This result shows that for employees in Gojek Bandung Company, Career Wellbeing has no significant correlation towards Employee Engagement. Based on the analysis, this condition might happen because the majority of employees in Gojek Bandung company are in the transition age between Millennials 
and Gen Z, specifically between 21 to 28 . Their tendency in having insecurity financial stability does impact them to focus more on the financial aspect and still have the tendency to changing jobs. For that reason, career wellbeing has not significantly affected the employee engagement.

Social Wellbeing in the result of the Multiple Linear Regression test is a non-significant factor for employee engagement with significance value 0.318. This result shows that for employees in Gojek Bandung company, Social Wellbeing has no significant correlation towards Employee Engagement. This condition could also happen because the employees are more focus on the fulfillment of safety needs first (can be seen from the result that Financial Wellbeing, which part of the Personal Security Needs, has the significant correlation with Employee Engagement) and subsequently, by Maslow's Hierarchy of Needs, is love and belonging needs, which including social wellbeing. Therefore, the employees feel they must fulfill good financial wellbeing first so that the social wellbeing can be considered as the factor to increase the employee engagement [17].

Physical Wellbeing in the result of the Multiple Linear Regression test is the most nonsignificant factor for employee engagement with the highest significance value up to 0.555 . This result shows that for employees in Gojek Bandung company, Physical Wellbeing has no significant correlation towards Employee Engagement. Based on the analysis according to Maslow's Hierarchy of Needs, taking concern into physical wellbeing (encompasses put attention on the intake habit, join gym classes) is a part of Self-Esteem. Self-esteem is the fourth stage of fulfillment, will become a considerable factor for engagement if the individual has formerly fulfilled the physiological, safety, and social needs. For that reason, this is aligned with the MLR result that shows financial wellbeing is the only factor that has a significant correlation with employee engagement and proves that employees in Gojek Bandung company are more focused on the fulfillment of financial aspects first.

Community Wellbeing in the result of the Multiple Linear Regression test has a borderline significant trend with a significance value of 0.095 . This result shows that for employees in Gojek Bandung company, Community Wellbeing has no significant correlation towards Employee Engagement. The condition could be explained with the Maslow's Hierarchy of Needs as well since the relationship between individual and the stakeholders they live with is included in the Social Needs stage. Employees in Gojek Bandung company have not put their attention on the social needs before the financial needs have been fulfilled. Moreover, with the majority of ages owned by employees ranging between 21 to 28, the tendency of people with mentioned age found joy in discover new things and willing to motivated themselves in a challenging situation. Therefore, a good state of community wellbeing has not significantly affected the engagement of employees in Gojek Bandung company.

\section{Conclusion}

Gojek as a startup company has to move fast in order to catch up to market demand and also to face fierce competition among the competitors. Based on this condition, it is important for Gojek to maintain employee performance as it is become the core resources. On the other hand, based on Employee Engagement Survey for preliminary study, the result shows that $86 \%$ of the employees in Gojek Bandung company are engaged. However, only $71 \%$ of the respondent stated that the amount of their stress is manageable. Based on the symptoms appeared, the problems of this research are to find factors of employee wellbeing initiatives and analyze which factor has significant correlation to increase the engagement of employees in Gojek Bandung company. 
Based on the analysis on the previous literature, Career Wellbeing, Social Wellbeing, Financial Wellbeing, Physical Wellbeing, and Community Wellbeing play a significant role to increase the engagement of employees. However, after conducting Multiple Linear Regression test on this research with Career, Social, Financial, Physical, and Community as the independent variable and Employee Engagement as the dependent variable, only one out of the five factor that has a significant correlation with the dependent variable.

Albeit the previous literature defined that the five factors can significantly affect the employee engagement, the engagement of employees in Gojek Bandung company does not affected by the four factors which are Career, Social, Physical, and Community. This study has discovered only Financial factor has a significant correlation towards the engagement of the employees in the company. After conducted further analysis, the condition appeared might be affected due to the fact that most of the employees are within the age of 21 to 28 years old, thus the employees have a willingness to discover new things and referred as a "Job Hopper" generation by Gallup [18]. For that reason, that is why Career and Community is not become a significant factor to increase the engagement for the employees. On top of that, based on analysis using Maslow's Hierarchy of Needs, employees are in the stage to fulfill their Security Needs, followed by Social Needs, Self-Esteem, and Self-Actualization. One of the factors that can fulfill the security needs is to have a good wellbeing of financial. If their financial wellbeing has been fulfilled, the other factor will be considered.

For conclusion, the engagement of employees in Gojek Bandung company can only significantly affected by having a good financial wellbeing, and not significantly affected by the career, social, physical, and community factor.

\subsection{Recommendation}

Based on the result of the research, several recommendations of Employee Wellbeing Initiatives program will be suggested to the company in order to improve the employee engagement.

a. This study has found that Financial Wellbeing is the factor that become a concern for the employees in the company. Therefore, the company has to put more attention to this factor in order to improve the employee engagement effectively. The initiatives that the company can prepare are:

- Ensure the employees' long-term financial security by offering several insurances such as health insurance and life insurance. This initiative can help the employees to have long-term financial peace of mind.

- Provide financial counseling program for the employees to discuss financial-related issues. Financial issues can be in any form, such as financial pressure, financial distress, unexpected expenses, and many other forms. The condition can cause stress for individuals thus affecting their productivity to a certain extent. In order to prevent this problem experienced by the employees, the employer can provide financial counseling program to help the employees prevent and or overcome such situations.

- Provide information regarding local businesses discount vouchers and promos. That information can help the employees to make a wise purchase decision and also inspire more manageable spending.

b. Based on the result of this research, albeit the other factor such as Career, Social, Physical, and Community have no significant correlation with Employee Engagement in Gojek Bandung Company, however, this factor can support the program as long as the employees' financial wellbeing has been fulfilled. According to Social Comparison 
Theory, individuals are fundamentally driven by evaluating and comparing themselves toward the other. As a consequence, individuals might want to achieve more than they already had up until they achieve their full potential.

\section{References}

[1] R. L. Mathias and J. H. Jackson, "Human resources management: sumber daya manusia," Erlangga: Bandung, 2006.

[2] S. R. Koev, A. Smahliuk, A. Nadtochii, L. Chepurda, and R. Dubas, "Determination of the Quality of Human Resources in Strategic Company Management," Acad. Strateg. Manag. J., vol. 18, no. 4, pp. 1-6, 2019.

[3] N. Bibu and A.-I. Munteanu, "The Importance Awarded to Human Resources and Human Resources Department in Companies from West Region of Romania," Rev. Manag. Comp. Int., vol. 17, no. 3, p. 196, 2016.

[4] E. Ries, The lean startup: How today's entrepreneurs use continuous innovation to create radically successful businesses. Currency, 2011.

[5] CB Insights, "The Complete List of Unicorn Companies," 2020. .

[6] Gojek, "Gojek Careers: Check out the current job openings at Gojek Tech," 2020. [Online]. Available: https://www.gojek.io/careers/.

[7] Kasasa, "Boomers, Gen X, Gen Y, and Gen Z Explained," 2019. [Online]. Available: https://www.kasasa.com/articles/generations/gen-X-gen-y-gen-z.

[8] M. R. Antony, "Paradigm shift in employee engagement-A critical analysis on the drivers of employee engagement," Int. J. Information, Bus. Manag., vol. 10, no. 2, pp. 32-46, 2018.

[9] M. J. Gorgievski, A. B. Bakker, and W. B. Schaufeli, "Work engagement and workaholism: Comparing the self-employed and salaried employees," J. Posit. Psychol., vol. 5, no. 1, pp. 8396, 2010

[10] A. Kohll, "Your Employee Engagement Strategy Needs More Wellness," 2018. [Online]. Available: https://www.forbes.com/sites/alankohll/2018/07/30/your-employee-engagementstrategy-needs-more-wellness/\#56421daf42b5.

[11] Gallup Inc., "Gallup Daily: U.S. Employee Engagement," 2020. .

[12] M. M. B. Islam, "Factors affecting quality of work life: an analysis on employees of private limited companies in Bangladesh,” Glob. J. Manag. Bus. Res., vol. 12, no. 18, 2012.

[13] C. Hancock and K. Cooper, "The case for linking employee wellbeing and productivity," Occup. Heal. Wellbeing, vol. 69, no. 11, pp. 14-15, 2017.

[14] E. C. Brüggen, J. Hogreve, M. Holmlund, S. Kabadayi, and M. Löfgren, "Financial well-being: A conceptualization and research agenda," J. Bus. Res., vol. 79, pp. 228-237, 2017.

[15] D. Lamond, R. Dwyer, S. Arendt, and M. Brettel, "Understanding the influence of corporate social responsibility on corporate identity, image, and firm performance," Manag. Decis., 2010.

[16] A. Hewitt, “Aon Hewitt's Model of Employee Engagement," Aon Inc., 2015.

[17] A. H. Maslow, Motivation and personality. Prabhat Prakashan, 1981.

[18] I. Gallup, "How millennials want to work and live.” Gallup Press Washington, DC, 2016. 